\title{
Analysis of an evacuation plan after an earthquake in El Progreso sector at Carabayllo district
}

\author{
Miguel Ángel Rodríguez Anticona, Eng ${ }^{1}$, Miguel Eduardo Ramírez Huamán, ${ }^{1}$, Luis Daniel Yupanqui Santiago, ${ }^{1}$ \\ Jonatán Edward Rojas Polo, $\mathrm{Mg}^{1}$ \\ 1Pontificia Universidad Católica del Perú, Perú,miguel.rodrigueza@pucp.pe,mramirezh@pucp.pe,d.yupanqui@pucp.edu.pe, \\ jrojasp@pucp.pe
}

\begin{abstract}
Lima is a city of 10 million inhabitants, and $60 \%$ of its population lives in slums settlements. Due to its location in the Circum Pacific Belt of Fire, this is a high-seismic activity area. Despite this fact, there is a serious lack of urban planning and natural disaster planning. After decades of neglect by Latin American governments in terms of planning, a quantitative risk assessment to determine population exposure is imperative, as well as it is also mandatory to propose an evacuation plan to mitigate, as far as possible, the post-earthquake effects. "El Progreso" sector located in Carabayllo, a Lima district in Peru, was selected as the case study because it is one of the slum settlements with the highest potential risk as it is located in a basin surrounded by hills due to the effects of informal constructions (such as ceilings). Filled with rocks and walls) their slopes have suffered much more deterioration than in other hillsides. In addition, this area is prone to debris avalanches, rock fragments, debris flows among other geologic hazards.

First step is start to identify all the existing risks such as: the height of buildings near the escape routes, illegally parked vehicles (mainly taxis and Peruvian motorcycle taxis), current traffic on the streets, distance to the evacuation areas, flow capacity of escape routes, flows of pedestrian moving in opposite directions, slopes and types of floor of escape routes, danger of avalanche and falling rocks. Then, risks will be classified using the Analytic Hierarchy Process AHP to obtain the cost function for roads. Then, two evacuation models based on linear programming are presented minimizing risk functions. Finally, two evacuation models based on linear programming are presented.
\end{abstract}

Keywords- Earthquake disaster, Linear Programming, Pedestrian evacuation model, Urban planning.

\section{LITERATURE REVIEW}

In this section, the main concepts that are the basis for the proposed research will be detailed.

\section{a) Disaster}

Before explaining the definition of an earthquake, the concept of disasters must be detailed. A disaster is defined as an interruption in the functioning of society. It causes a great amount of destruction of human resources, material, environmental, cultural, economic resources, etc. [1]. These are classified depending on the causal phenomenon, whether natural or anthropological [2]. Among the main natural disasters are earthquakes, tsunamis, tornadoes, volcanic eruptions, etc. Disasters can be minimized or, at best, avoided if communities adapt their lifestyles and future development in the natural hazards that surround the environment in which they find themselves.

Digital Object Identifier (DOI): http://dx.doi.org/10.18687/LACCEI2018.1.1.168 ISBN: 978-0-9993443-1-6

ISSN: $2414-6390$

\section{b). Disaster management cycle}

The disasters present a management cycle, which will be presented and detailed below according to the information, provided [3].

Prevention: The action within this segment is designed to prevent the occurrence of a disaster or prevent such occurrence from having harmful effects on the communities or their facilities.

Mitigation: Action within this segment usually takes the form of specific programs aimed at reducing the effects of the disaster on a nation or community. For example, some countries consider the development and application of building codes that can reduce damage and loss in the event of earthquakes and cyclones, such as in the mitigation category. Other countries may consider such building codes as being in the prevention category; some recent developments of anti-seismic buildings have undoubtedly influenced this perspective.

Preparedness: In general, it is considered to include measures that allow governments, organizations, communities and individuals to respond quickly and effectively to a disaster. Examples of preparation measures are:

- Formulate and maintain a valid and updated disaster plan that can be carried out when necessary.

- Special provisions for emergency actions, such as evacuating populations or temporarily displacing them to safe places.

- Provide warning systems.

- Effective communication when the emergency occurs.

- Public education and awareness about disaster management.

- Training programs for disaster management, such as simulations.

Disaster Impact: This segment is the point in the management cycle in which the disaster occurs. For example, when a cyclone ravages a particular country or area. It must be borne in mind that including it serves as a reminder that, at the time of disaster management, this impact may vary depending on type of disaster that happens.

Response: The response measures are usually those that are taken immediately before and after disaster's impact. Such measures are aimed primarily at saving lives and protecting

16 $^{\text {th }}$ LACCEI International Multi-Conference for Engineering, Education, and Technology: "Innovation in Education and Inclusion", 19-21 July 2018, Lima, Peru. 
property, and at coping with the immediate interruption, damage and other effects caused by the disaster. Typical measures include:

- Implementation plans.

- Initiation of the disaster plan.

- Search and rescue.

- Emergency food supply, shelter, medical assistance, etc.

- Evacuation.

In the present research article, focus will be mainly on the stages of preparation, disaster's impact and the last one that has just been presented.

Recovery: This is the process by which communities and the nation receive assistance to be able to return to their proper functioning level after the occurrence of a disaster. The recovery process can be very long, taking 5-10 years or even longer depending on the affected area.

Development: This segment provides the link between activities related to disaster management and national development. Its inclusion in the disaster cycle serves to ensure that the results of the disaster are effectively reflected in future policies in the interest of national progress.

\section{c). Earthquake}

According to [4], an earthquake happens when a sudden release of energy causes the earth to vibrate and shake, associated with the passage of waves of energy released at its source. Earthquakes can be extremely devastating and costly events, sometimes killing tens or even hundreds of thousands of people.

Among the main consequences, are the effects on the floor. One of the main effects, which will be studied in this research article, are landslides. Landslides include several types of faults and earthworks, such as rockfalls, deep slope failure and surface debris flows. These failures are generated by the loss of resistance to cutting in the ground. The landslides caused by earthquakes sometimes cause more destruction than the earthquakes themselves. The immediate dangers of landslides are the destruction of buildings. The size of the area affected by the earthquake can induce landslides depending on the magnitude of the earthquake, its focal depth, the topography and geology and duration of the earthquake. For this reason, is that people who are located near these areas where there is a greater probability of occurrence of a landslide should evacuate after the earthquake as soon as possible.

\section{d). Evacuation time}

Within the occurrence of this natural disaster, there is a series of events, which make up the total time of the evacuation. In the book published by [5], these events were detailed in the event that the disaster is a fire; however, this can be replicated for any other type of disaster. Through a timeline model, it was determined that the total time of the event occurred during a disaster (RSET) is divided into the detection time, the alarm time, the preparation time, which divides into the Recognition time and response time and travel time. Travel time is the time needed for evacuees to walk to safe areas. Among the possible safe areas to which evacuees can opt are green areas or parks. Within the stages of the disaster management cycle, this time is located in the Response stage.

\section{e). Previous optimization models}

Modeling no-notice mass evacuation using a dynamic traffic flow optimization model: In this research article, published [6], it is detailed that there are two types of evacuations induced by disasters: those of short notice and nonotice. In the case of short-notice evacuations, they are those that have a desirable waiting time of between 24-72 hours [7] allowing risk management agencies to determine a priori evacuation strategies based on the expected spatial-temporal impact of the disaster. Examples of short-notice evacuations are events such as hurricanes, floods and fires. On the contrary, an evacuation without warning occurs when a large and unexpected incident occurs. The evacuation that takes place immediately after the occurrence of a disaster is defined as a "no-notice evacuation" [8]. When a disaster occurs without prior notice that requires a mass evacuation, a preconceived evacuation plan can be immediately put into action. Traffic control and routing strategies need to be updated quickly and frequently according to traffic conditions. The main contribution of this research article is that it proposes a network transformation and demand modeling technique that allows determining the optimal evacuation destination, the allocation of traffic and evacuation schedule decisions that has been formulated in a model of optimal traffic flow optimization by solving these decisions simultaneously.

Evacuation transportation planning under uncertainty: A robust optimization approach: In this article published [9], it is explained the focus on the uncertainty of demand that can lead to significant risk costs during evacuation, where loss of life or property may appear. To do this, they developed a routing model for evacuation transport planning in extreme conditions. By focusing on the cost of risk, they showed the importance of the robustness of the data and the constraints of the model. More interestingly, they determined that a robust solution improves both viability and quality compared to a solution with nominal data. The main contribution of this research article is that it provides a basis for future simulation analysis in risk management, considering the proposed variability of the offers (number of evacuating) and the capacities of the evacuation centers (safety zones).

Generic Flow Model: In this model presented [10], is a generic formulation of the minimum cost dynamic network

$16^{\text {th }}$ LACCEI International Multi-Conference for Engineering, Education, and Technology: "Innovation in Education and Inclusion", 19-21 July 2018, Lima, Peru. 
flow problem that builds the basis of the developed evacuation models (adapted from maximal dynamic flow model presented in [11]). In the first case, the model has flow enforcement constraints, flow conservation constraints and capacity constraints. After that, the waiting in nodes was included with the capacity limit for each node per point in time. For the present research, this case (with waiting in nodes) won't be considered in the model.

\section{INTRODUCTION AND INFORMATION COLLECTION}

The district of Carabayllo is the most extensive of the 43 districts of the province of Lima. It is located north of the city, bordered on the north and northeast by the district of Santa Rosa de Quives of the province of Canta, on the south it borders the district of Comas, on the east with the province of Huarochirí and on the west with the Puente Piedra district and the Ancón district. Inside this district, there is located the El Progreso sector. It has an aproximately population of 21,160 inhabitants. These population lives, in the majoritie of cases, in slums like the one shown in fig1.

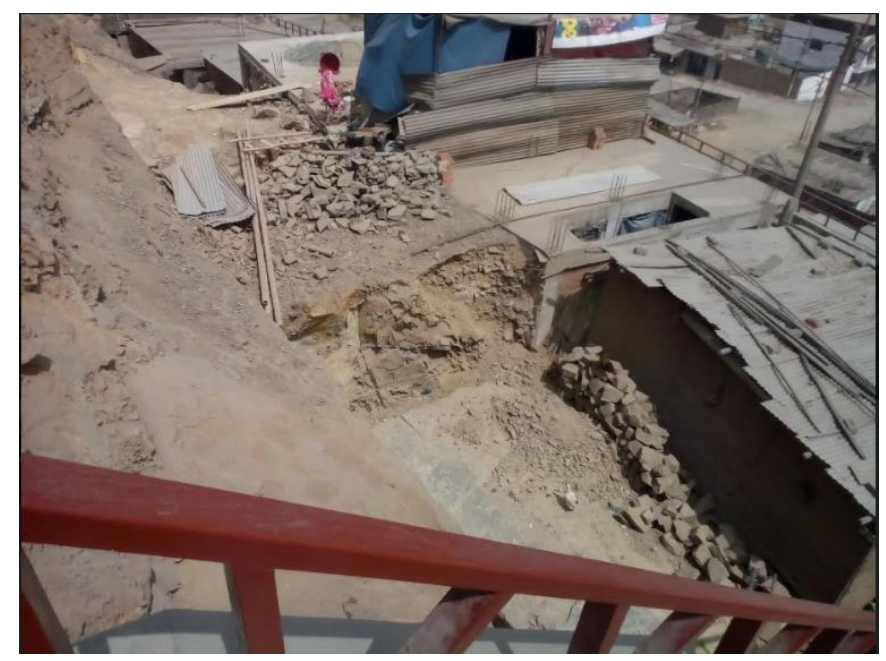

Fig. 1 Example of houses in El Progreso Sector

As can be seen, they live in humble homes and the location of houses are distributed along the slums. Despite the high slopes of the slums, other problem identified in this sector if an earthquake happens are the rock fragment that are located in many parts of the slums and, in many cases, this rocks are above the houses like in the next example in fig 2 .

Another problem identified is the fact that Peruvian government always postpone urban and security policies to slums, when they are the most affected in case of a natural disaster for example. That might happen because government have fear of legitimize slums or because they are just a high cost so it is simpler to forget them.

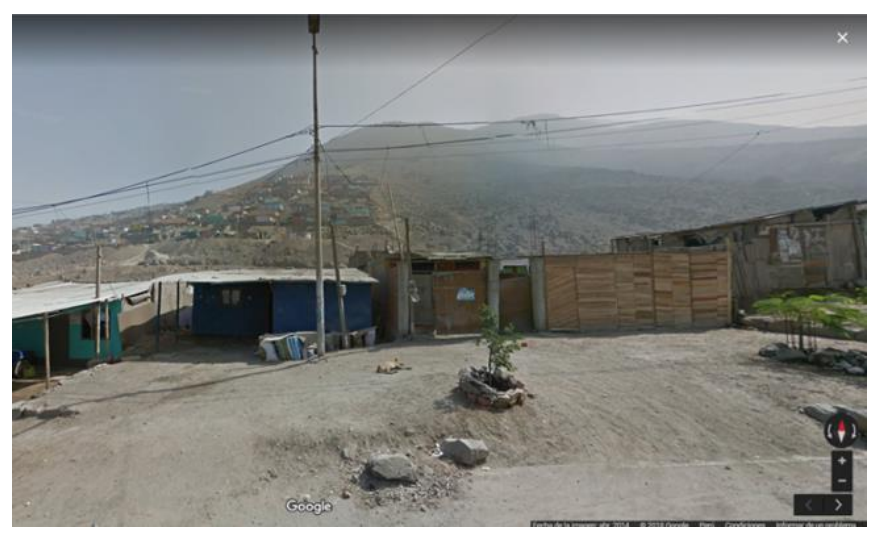

Fig. 2 Rock fragments above the houses in El Progreso Sector

Therefore we approach the lack of security policies to slums proposing an optimal routes the inhabitants of " $E l$ Progreso", slum inside of Carabayllo district in Lima (see fig. 3 ), should use after an earthquake. In order to obtain relevant information related to the number of inhabitants (evacuating). The information collected by the Municipality of Carabayllo district in 2016 after the census conducted in El Progreso sector is used in this paper.

This information provided a cadastral map of total dwellings and inhabitants registered up to that date. For the evacuation points, Google Maps was used to measure the total area of the existing sport fields and green zones. Based on it, and considering an area of 0.25 meters per pedestrian [12], the total capacity of each evacuation point was determined, nevertheless a gap is found between evacuation capacity and population (21 160 inhabitants) of "El Progreso", this gap of 4 113 pedestrians is covered adding two schools and one clearing. Is posible that those two schools might collapse in an earthquake but, for the simplicity of this model, it is assumed that this will not happen. In fig. 3 initial nodes where pedestrians start to evacuate are presented in yellow and red, if they are in very danger zones are presented in red and evacuation nodes are presented in green, intermediate nodes that are nodes where pedestrians just transit momentarily are presented in yellow also.

Google Maps was used to determine the average width of the streets. A sample of 30 data were taken, obtaining an average of 6.7 meters. In the case of the slopes, the level curves presented in GPS Visualizer were used; the height difference between 2 points over the distance between them, gives these slopes as result. In order to determine distances, Google Earth and Mapper was used; WGS84 coordinates were obtained in the southern hemisphere of the initial, intermediate and final nodes in evacuation.

Thus, using the Pythagorean formula and adding the Root factor as it is a non-Euclidean distance, distances between nodes were obtained. 


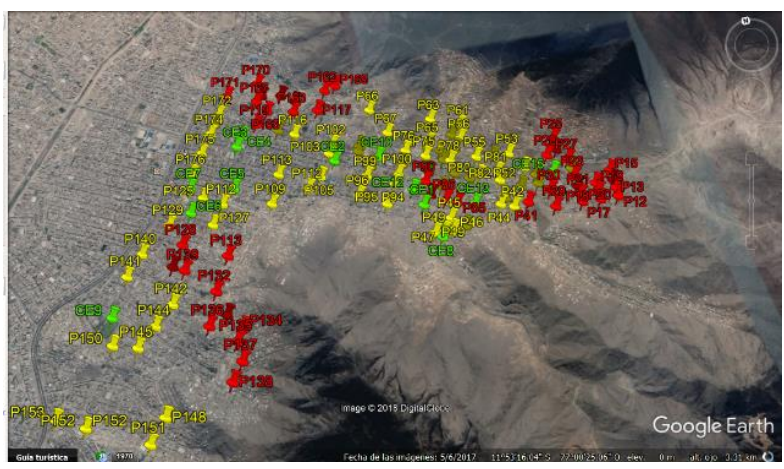

Fig. 3 Map of El Progreso Sector with nodes used

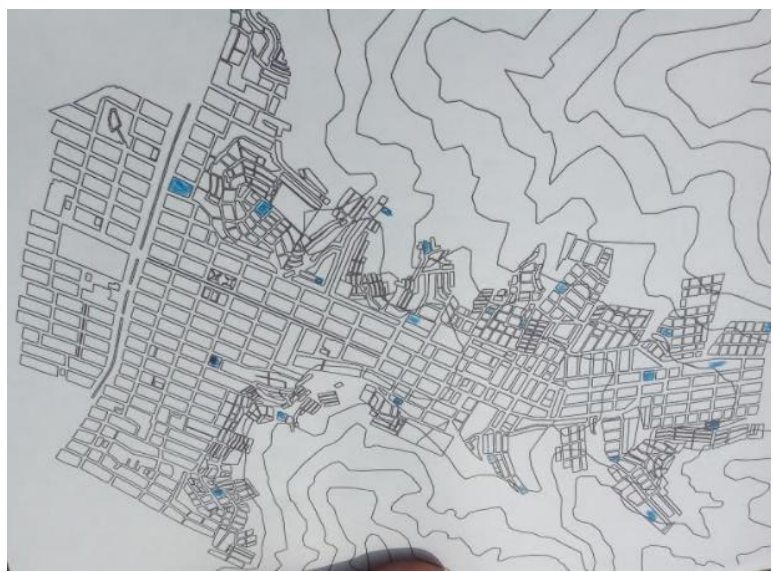

Fig. 4 Stratified Map of El Progreso Sector and its nodes

\section{III . RISK FUNCTION}

The risk that pedestrains have at the time of evacuation is obtained considering how long is the route they have to travel, how much space (width) they have to be able to move freely and what are the dangers that have the routes through which the residents will have to travel, analyzing not only the type of soil through which they will have to pass, but also mass movements (such as avalanches and debris flows), etc.

\section{Where:}

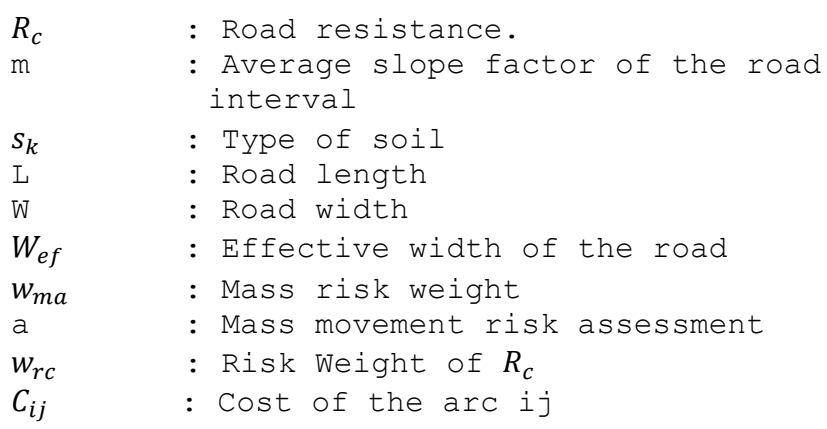

Among the risks that have been exemplified above, these can be divided into two large groups: risk by mass movement and road resistance
1) Risks by mass movement. These geological risks are the main threat to the inhabitants in the event of aftershocks of a previous earthquake, because many of them can cause the direct death of pedestrians, if they are on the road where they are traveling. These risks are divided into the following factors that will be detailed below:

- Geodynamics

- Geologic factors

- Geomechanics

- Geomorphologic factors

2) Road Resistance. To calculate this Resistance, it will be considered an analogy of the electrical resistances of the electrical conductors as explained by [13]. In his article, he proposes to use the road resistance as $R_{C}=\mathrm{L} / \mathrm{W}$ directly proportional to the road length, but inversely proportional to the width of the road. This paper propose to add to this equation the average slope factor in that interval and type of soil:

$$
R_{c}=m * s_{K} * \frac{L}{W_{e f}}
$$

The effective width of the road $W_{e f}$ will be determined by subtracting interferences in the road $\mathrm{W}$, such as obstruction obstacles of the rubble of destroyed buildings, illegal parking of motorcycles, cars, traffic jam, etc.

The type of soil will be determined by whether it is cement or gauge where cement would have a value of $S_{1}=$ 0.33 , and gauge $S_{2}=1$

With regard to the slope factor of each arc:

- If the average slope $<-6 \%$, then $\mathrm{m}=3$

- If the average slope ranges are $[-6 \%, 0 \%[$, then $\mathrm{m}=2$

- If the average slope ranges are $[0,4 \%[$, then $\mathrm{m}=1$

- If the average slope $>4 \%$, then $\mathrm{m}=3$

These different risks are analyzed using the AHP method in order to quantify the importance of each risk with respect to the others with the following results:

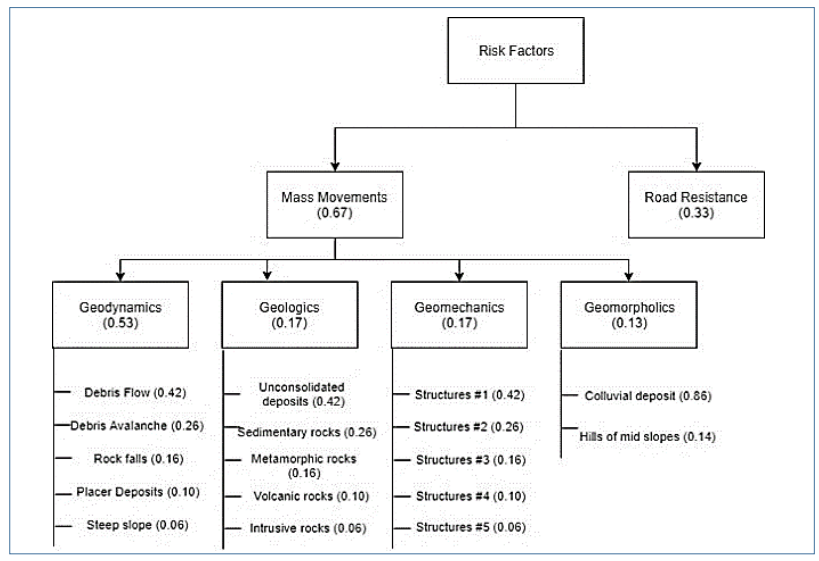

Fig. 5 Risk Factors 
Then the risk cost of each arc ij is determined with the following formula:

$$
C_{i j}=w_{r c} * R_{c}+w_{m a} * a
$$

In fig 6. shows a map with mass movement risk assessment provided by [14]:

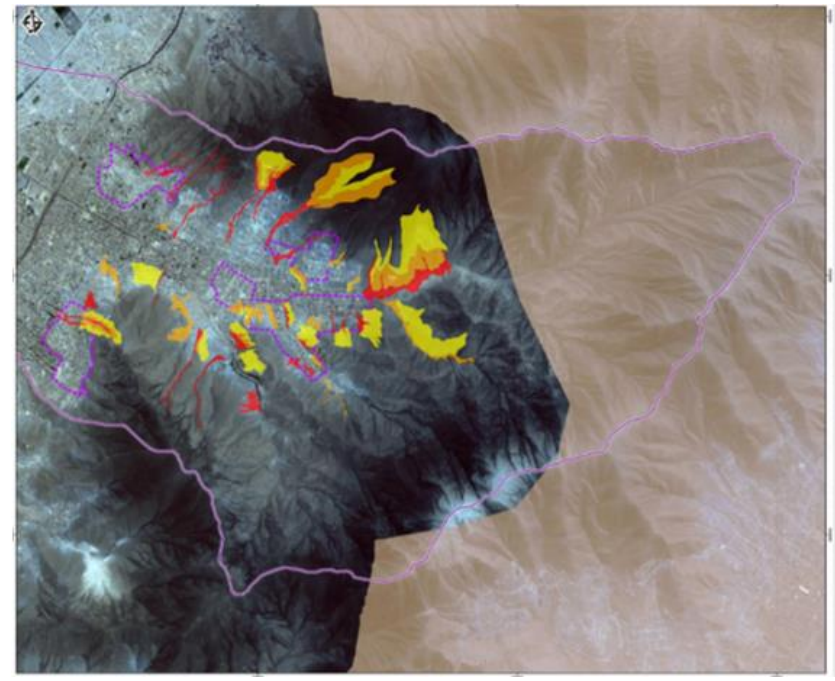

Fig. 6 Hazard map of mass movements

\section{ROAD CAPACITY}

According to [15], the optimum space for pedestrian evacuation is over $3.7 \mathrm{~m}^{2} /$ pedestrian. Any space smaller than $3.7 \mathrm{~m}^{2} /$ pedestrian reduce evacuation speed and cause pedestrian crashes.

Using a safety factor in case of overcrowding at certain points while starting an evacuation, means that we are multiplying by 1.5 the best space proposed in [15] obtaining then an ideal space of $5.5 \mathrm{~m}^{2} /$ pedestrian.

This new factor will be used to quantify the maximum capacity of arcs, as follows:

$C_{\text {arco } \_i j}=\frac{L * W_{e f}}{5.5}$

In order to calculate the capacity of arcs, if a segment of the arc has a different $W_{e f}$, the smallest one will be taken as it is a bottleneck.
Two models will be presented, in the first where time will not be considered as a dimension and the second where it will be considered. For both models, the assumptions are:

- Pedestrians share the same features.

- Each initial node have a guide or leader who knows the appropriate route to evacuate.

- Pedestrians and guides are properly trained and pedestrians follows to guides.

- Neither dead nor injured in evacuation process.

\section{Model I}

In this model, the main objective will be to minimize the risk about how to pedestrian must to evacuate. Therefore, the model will define which route the pedestrians should follow until they reach the different evacuation centers. In this case, the dimension of time will not be considered.

\section{Decision variable}

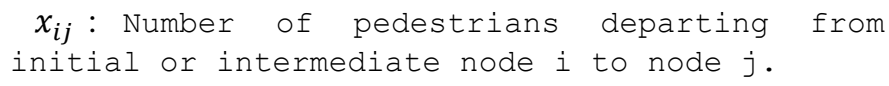

Index

$R$ index $r \in R$ a set of evacuation or final nodes i.e. $r=1, \ldots, R$

$K$ index $k \in K$ a set of intermediate nodes where $k=1, \ldots, K$

$N$ index $n \in N$ a set of initial nodes where $n=$ $1, \ldots, N$

$I$ index $i \in I$, a set where $i=1, \ldots N, N+1, \ldots$, $N+K$ i.e. $N+K=I$

$J$ index $j \in J$, a set where $j=1, \ldots R, R+1, \ldots, R$ $+N, R+N+1, \ldots R+N+K$ i.e. $R+N+K=J$

\section{Parameters}

$C_{i j}$ : Cost of the arc ij

Qevc $_{i}$ : Number of pedestrians in the initial and intermediate node $j$

Qrun $_{r}$ : Capacity of pedestrians in the evacuation or final node $r$

$C_{\text {arco } i j}$ : Maximum capacity of pedestrians in the $\operatorname{arc} i j$

$L t_{i j}$ : Length of time elapsed to move from node $i$ to node $j$.

\section{MODEL}

$16^{\text {th }}$ LACCEI International Multi-Conference for Engineering, Education, and Technology: "Innovation in Education and Inclusion", 19-21 July 2018, Lima, Peru. 


$$
\operatorname{Min} \sum_{j=1}^{J} \sum_{i=1}^{I} x_{i j} \cdot c_{i j}
$$

Subject to

$\sum_{i=1}^{I} x_{i r}=$ Qrun $_{r}, r \in R$

$\sum_{i=1}^{I} x_{i, j}-\sum_{j-r}^{J} x_{i, j} \leq-Q e v c_{j-r}, j \geq r+1, i \in I$

$x_{i j} \leq C_{\text {arco_ij }}, i \in I y j \in J$

$x_{i j} \geq 0$ and integers, $i \in I, j \in J$

The linear function (5) minimizes the function of risk costs depending on how pedestrians evacuate.

Restriction (6) refers to the relation of pedestrians evacuating with the capacity of the areas where they evacuate, as they should not exceed the capacity of the evacuation nodes.

Restriction (7) refers to the equilibrium equation of initial nodes, intermediate nodes and final nodes where the pedestrians are evacuating.

Restriction (8) is the maximum capacity of pedestrians who can evacuate in each arc as they have a length and width as limitations.

Restriction (9) refers that the variables must to be positive and integers.

\section{Model II}

Unlike the previous model, the variable time will be considered within the decision variable. In order to formulate it, the model proposed in [10] was taken as reference; however, some variations were made in order to adapt them to the model of the present article.

- In this model, the fictitious start and end nodes that were considered in [10] have not been considered.

- The evacuation nodes that we present in this model that correspond to parks, green areas, have a limited capacity unlike the equations proposed in [10], because in this case the evacuation of pedestrians is being modeled and not evacuation of vehicles, where the following nodes (roads) are safe and therefore, it is not considered a capacity in the final nodes.

- As mentioned above, waiting times will not be considered in the transshipment nodes, because in this case the pedestrians, rationally, do not expect a road to be vacated, but will look for another one that is available to continue evacuating.

- In this case, time is not the main parameter to evaluate in this model, because the most important thing is that the pedestrians are as far away as possible from roads or places where they will go through the dangers caused by mass movements, what this will not be considered as an additional cost in the objective function.

Decision variable

$x_{i j t}$ : Number of pedestrians departing from initial or intermediate node $i$ at time $t$ to node $j$.

Index

The only index that is going to be added compared to model I is time, which will be a discrete variable with integer values $(0,1,2,3$, etc $)$.

$T$ index $t \in T$ a set of time nodes i.e. $t=$ $0, \ldots, T$

$$
\operatorname{Min} \sum_{t=0}^{T} \sum_{j=1}^{J} \sum_{i=1}^{I} x_{i j t} \cdot c_{i j}
$$

\section{Subject to}

$\sum_{t}^{T} \sum_{i=1}^{I} x_{i r t}=$ Qrun $_{r}, r \in R$

(if $L t_{i j} \geq t$ then 0 else $\left.\sum_{i=1}^{I} x_{i, j,\left(t-L t_{i j}\right)}\right)-\sum_{i=1}^{I} x_{j, i, t} \leq$

$-Q e v c_{i}, j \in J, t \in T$

$x_{i j t} \leq C_{\operatorname{arco}_{i j}}, i \in I, j \in J, t \in T$

$x_{i j t} \geq 0$ and integers, $i \in I, j \in J, t \in T$

The linear function (10) is similar to model I, with the difference of the time's dimension inclusion in decision variable.

Restriction (11) is similar to restriction (6), but, in this case, the pedestrians arrive to some evacuation node in any moment of time.

Restriction (12) have a meaningful difference with the restriction (7) that is the inclusion of the parameter $L t_{(I, j)}$. If $L t_{(I, j)}-\mathrm{t}$ is $<0$, it represents that the pedestrians doesn't start from node $\mathrm{i}$ at time $\mathrm{t}$ indicated because is impossible depart from any node in negative times. Therefore, any $x_{i, j,\left(t-L t_{i j}\right)}$ that meets the aforementioned condition will have a value of 0 .

Restriction (13) is the maximum capacity of pedestrians who can evacuate in each arc as they have a length and width as limitations. As in Equation (12) another limitation of these capabilities is time, because at a given time, there could be the limit number of pedestrians in the arc; however, in another moment, these pedestrians already moved to another arc, so that

16 $^{\text {th }}$ LACCEI International Multi-Conference for Engineering, Education, and Technology: "Innovation in Education and 
this arc could be occupied by pedestrians different from the previous moment.

Restriction (14) refers that the variables must to be positive and integers.

\section{RESULTS}

The I and II models are solved using the AMPL software. A comparison between model I and model II is made, where for the first one an objective function of 367159775 is obtained, while for model II, after having discretized the time with integer values $(>=0)$ with one minute difference between each value, obtains an objective function of $\underline{313} 340$ with a significant reduction in the cost of risk by $99 \%$. The reason why the reduction has been very significant is due to the fact that in model II, the use of arcs ij is better than in model I.

It must be taken into account that the model II in a time horizon $t$ in the model does not mean that people arrive in a maximum time of $\mathrm{t}$ but that it is the last time $\mathrm{t}$ where the pedestrians leave in previous nodes towards the evacuation nodes, therefore, it should be added to the value t a $\max \left(L t_{(I, j)}\right)$ to obtain the maximum time of arrival. In this case, the $\max \left(L t_{(I, j)}\right)=5 \mathrm{~min}$, therefore if the parameter is set as $\mathrm{t}=8$ minutes it means that the last evacuating would be arriving in a maximum time of $\mathrm{t}+\max \left(\operatorname{Lt}_{(I, j)}\right)$, that is, 13 minutes.

The model II is then processed for different instances of $\mathrm{t}$ of 10 minutes in 10 minutes, in the blue line it shows the model with the current risk costs, and in the green line the risk costs improved by the elimination of obstructions resulting from illegal parking of cars and mototaxis or street closed by informal markets, and asphalt every street that is gauge.

For the time $\mathrm{t}=10$ with the proposed improvements a reduction of $1 \%$ is obtained, in time $=30$ minutes the proposed improvements obtain a risk reduction in $4 \%$ and the objective function of both remain constant from $t=80$ minutes to $t=\infty$.

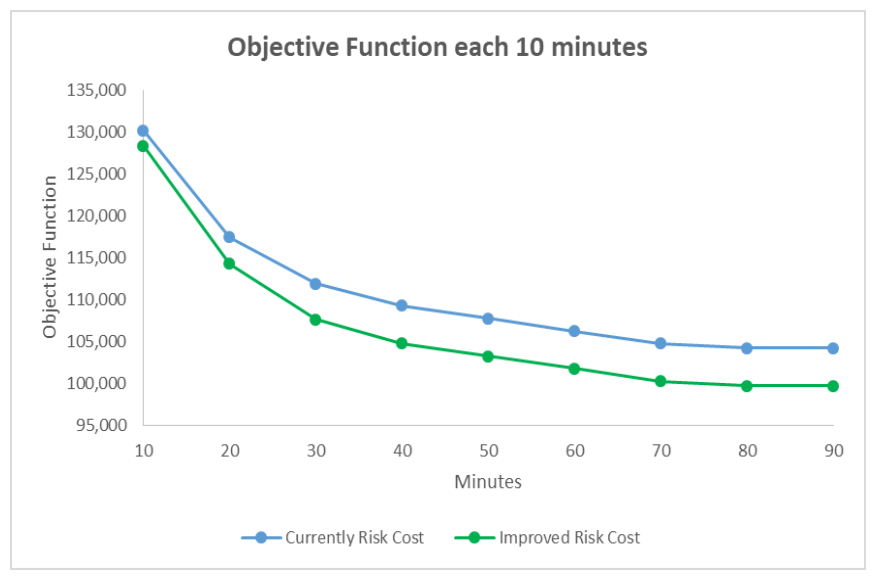

Fig. 7 Objective Function each 10 minutes
The fig 7 shows how the smaller the evacuation horizon the risk increases, in the case of earthquake evacuation time is not crucial.

The fig 8 shows a small example of how the pedestrian movement happen in Model II for $\mathrm{t}=10$.

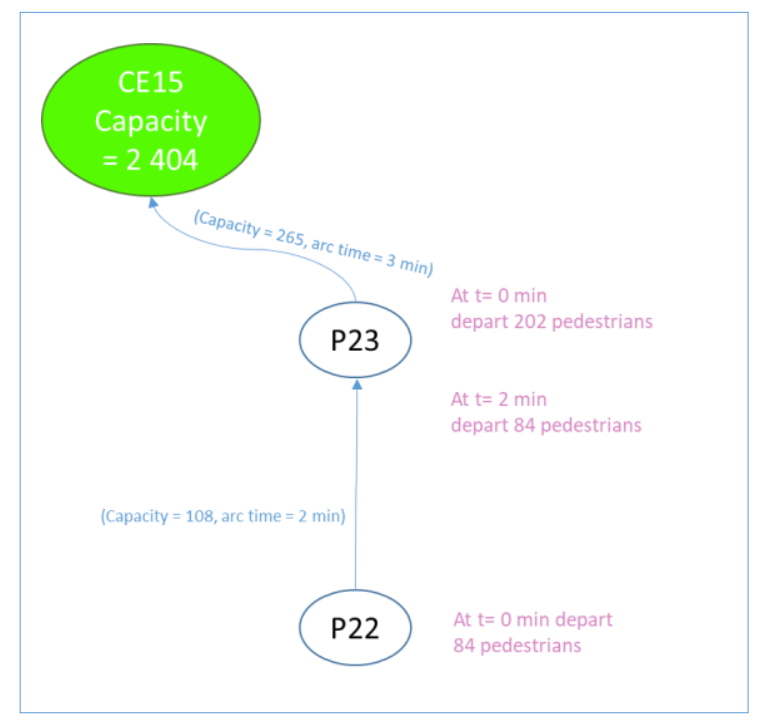

Fig. 8 Example about how pedestrian move according to model II

\section{CONCLUSION}

The two proposed models offer a quantitative evaluation of urban development and safety improvements to reduce risks during evacuation at the same time that presents optimal routes to evacuate depending on where they live. In which model II significantly reduces the evacuation risk by $99 \%$ with respect to model I, but has a much more difficult implementation due to the coordination effort required.

\section{RECOMMENDATIONS}

- Place strategically wayfinding in street in order to improve discipline when evacuating

- This model with some adjustments for dynamic environments can be implemented in the future smart cities

- Elder pedestrians and persons with disabilities need a special guides by each initial node

- Migrate people who lives in place most dangerous to social housing complex is mandatory to save their lives.

- Evaluate optimal locations to social house complex.

- Migrate people who lives in the most dangerous places to social housing complex that must be builded in the safe place of El Progreso.

16 $^{\text {th }}$ LACCEI International Multi-Conference for Engineering, Education, and Technology: "Innovation in Education and 


\section{REFERENCES}

[1] INDECI (2004). "Plan nacional de prevención y atención de desastres Tomo 1". Retrieved from: http://sinpad.indeci.gob.pe/UploadPortalSINPAD/plan_nacional_preven_ 15ene041.pdf

[2] Lavell, A., (1997). Viviendo en riesgo. Comunidades vulnerables y prevención de desastres en América Latina, México D.F, México: LA RED.

[3] Carter, W., (2008). Disaster management: a disaster manager's handbook. Dos volúmenes. Mandaluyong City, Filipinas: Asian Development Bank.

[4] Kusky, T., (2008). EARTHQUAKES: Plate Tectonics and Earthquake Hazards. New York. Estados Unidos de América: Infobase Publishing.

[5] Cuesta, A., (2016). Evacuation Modeling Trends. Suiza: Springer.

[6] Chiu, Y., Zheng, H., Villalobos, J. and Gautam, B. (2007). Modeling nonotice mass evacuation using a dynamic traffic flow optimization model. IIE Transactions, 39(1), pp.83-94.

[7] Wolshon, B. (2002) Planning for evacuation for New Orleans. Institute of Transportation Engineers Journal, 72(2), 44-49.

[8] Anon (2005) ITS to the rescue. US Department of Transportation, http.//www.its.dot.gov/eto/eto rescue.htm.

[9] Yao, T., Mandala, S. and Chung, B. (2009). Evacuation Transportation Planning Under Uncertainty: A Robust Optimization Approach. Networks and Spatial Economics, 9(2), pp.171-189.

[10]Bretschneider, S., (2013). Mathematical Models for Evacuation Model in Urban Areas. Bielefeld, Alemania: Springer.

[11]Ford LR Jr, Fulkerson DR (1958) Constructing maximal dynamic flows from static flows. Oper Res 6(3):419-433.

[12]CGCOII. "[254] Aforo y densidad de ocupación en locales con espectadores de pie". Retrieved from: https://ingenierosindustriales.es/consultas-cte/254-aforo-y-densidad-deocupacion-en-locales-con-espectadores-de-pie/

[13]Zhang, N., Huang, H., Su, B., \& Zhao, J. (2015). Analysis of dynamic road risk for pedestrian evacuation. Physica A: Statistical Mechanics and Its Applications, 430, 171-183. https://doi.org/10.1016/j.physa.2015.02.082H. Simpson, Dumb Robots, $3^{\text {rd }}$ ed., Springfield: UOS Press, 2004, pp.6-9.

[14]Díaz, A., (2015). Estudio de peligros por inundaciones, flujos rápidos y movimientos en masa desencadenados por efectos sísmicos en la quebrada El Progreso, Lima, Perú: CIP.

[15]Fruin, J. J. (1971). Designing for pedestrians: A level of service concept. Highway Research Record, 355,1-15. Gelenbe,

$1^{\text {th }}$ LACCEI International Multi-Conference for Engineering, Education, and Technology: "Innovation in Education and Inclusion", 19-21 July 2018, Lima, Peru. 